\title{
Article \\ Differing Life-History Strategies of Two Mycoheterotrophic Orchid Species Associated with Leaf Litter- and Wood-Decaying Fungi
}

\author{
Yuki Ogura-Tsujita ${ }^{1,2, * \mathbb{C}}$, Kenshi Tetsuka ${ }^{3}$, Shuichiro Tagane ${ }^{4}$, Miho Kubota ${ }^{1}$, Shuichiro Anan ${ }^{1}$, \\ Yumi Yamashita ${ }^{5}{ }^{\infty}$, Koichi $^{\text {Tone }}{ }^{6}$ and Tomohisa Yukawa ${ }^{5}$ \\ 1 Faculty of Agriculture, Saga University, 1 Honjyo-machi, Saga 840-8502, Japan; \\ 13251019@cc.saga-u.ac.jp (M.K.); 15251002@cc.saga-u.ac.jp (S.A.) \\ 2 The United Graduate School of Agricultural Sciences, Kagoshima University, 1-21-24 Korimoto, \\ Kagoshima 890-8580, Japan \\ 3 Yakushima Evergreen Broad-Leaved Forest Network, Isso, Yakushima-machi, Kumage-gun, \\ Kagoshima 891-4203, Japan; yattaneyoca@gmail.com \\ 4 The Kagoshima University Museum, 1-21-30 Korimoto, Kagoshima 890-0065, Japan; stagane29@gmail.com \\ 5 Tsukuba Botanical Garden, National Museum of Nature and Science, 4-1-1 Amakubo, Tsukuba, \\ Ibaraki 305-0005, Japan; rsc76297@nifty.com (Y.Y.); yukawa@kahaku.go.jp (T.Y.) \\ 6 Okinawa Municipal Museum, 2-19-6 Uechi, Okinawa 904-0031, Japan; ktonetombo@city.okinawa.lg.jp \\ * Correspondence: ytsujita@cc.saga-u.ac.jp
}

check for updates

Citation: Ogura-Tsujita, Y.; Tetsuka, K.; Tagane, S.; Kubota, M.; Anan, S.; Yamashita, Y.; Tone, K.; Yukawa, T. Differing Life-History Strategies of Two Mycoheterotrophic Orchid Species Associated with Leaf Litterand Wood-Decaying Fungi. Diversity 2021, 13, 161. https://doi.org/ 10.3390/d13040161

Academic Editor: Michael Wink

Received: 16 February 2021

Accepted: 6 April 2021

Published: 8 April 2021

Publisher's Note: MDPI stays neutral with regard to jurisdictional claims in published maps and institutional affiliations.

Copyright: (c) 2021 by the authors. Licensee MDPI, Basel, Switzerland. This article is an open access article distributed under the terms and conditions of the Creative Commons Attribution (CC BY) license (https:/ / creativecommons.org/licenses/by/ $4.0 /)$.

\begin{abstract}
Mycoheterotrophic orchids depend completely on mycorrhizal fungi for their supply of carbon. The life-history traits of mycoheterotrophic plants (MHPs) can differ according to the characteristics of the associated mycorrhizal fungi. We compared the life-history strategies of two mycoheterotrophic orchids associated with wood- and leaf litter-decaying fungi over a maximum of six years of field monitoring. Seventy percent of the aboveground stems of Erythrorchis altissima, associated with wood-decaying fungi, disappeared from the host wood within two years after tagging, likely due to nutrient depletion. In contrast, Gastrodia confusa, associated with leaf litterdecaying fungi, occurred continuously (18 to 108 fruiting stalks) every year within a small-scale plot $(12 \times 45 \mathrm{~m})$ for six years through seed and clonal propagation. Our results support the idea that mycoheterotrophic orchids associated with wood-decaying fungi disappear from their habitats due to nutrient depletion after their host wood has mostly decayed, while mycoheterotrophic orchids associated with leaf litter-decaying fungi can survive in small-scale habitats where substantial leaf fall regularly occurs to sustain the associated fungi. Our study provides basic information about a unique life-history strategy in MHPs associated with saprotrophic fungi and an understanding of the variation in life-history strategies among MHPs.
\end{abstract}

Keywords: achlorophyllous plants; mycoheterotrophy; mycorrhizal associations; Orchidaceae; saprotrophic fungi

\section{Introduction}

Mycoheterotrophic plants (MHPs) are completely reliant on mycorrhizal fungi for their supply of carbon throughout their lifecycle [1]. These plants lack foliage leaves and spend most of their life cycle underground; they emerge aboveground only during their reproductive phase. This creates difficulties in the field monitoring of these species; thus, the life-history strategies of MHPs remain poorly understood. Because these plants survive only in habitats where their fungal partners are present, their life-history traits, such as their life span, reproduction and recruitment, may depend on those of their associated mycorrhizal fungi. Since a variety of ecologically and phylogenetically different fungal groups participate in mycoheterotrophy, the life-history strategies of MHPs are expected to differ among the associated fungal groups. Two main mycorrhizal systems support carbon 
acquisition by MHPs, namely, (1) the mycorrhizal fungi associated with autotrophic plants and (2) free-living saprotrophic (SAP) fungi [2]. (1) The former system includes arbuscular mycorrhizal (AM) and ectomycorrhizal (ECM) fungi, and the MHPs associated with AM (AM-MHPs) and ECM fungi (ECM-MHPs) obtain carbon from neighbouring autotrophic plants through shared mycorrhizal fungi [2]. This tripartite system allows MHPs to access the carbon flows in common mycorrhizal networks. (2) The latter system depends on carbon from the forest carbon cycle, i.e., plant debris. Mycorrhizal fungi associated with SAP-MHPs include leaf litter- and wood-decaying fungi, and SAP-MHPs obtain carbon from plant debris through decomposition [3]. Long-term field monitoring of this tripartite system was performed for several species, such as Corallorhiza odontorhiza (Willd.) Nutt. [4,5] and Corallorhiza striata Lindl. [6]. These studies revealed the climatic factors that affect the abundance and distribution of ECM-MHPs [4,6] and long-term demographic impacts on plant reproduction [5]. However, studies regarding long-term field monitoring of SAPMHPs are scarce. Although several field surveys revealed local distribution patterns [7] and the reproductive ecology [8-10] of SAP-MHPs, these studies were performed over only a few years, and a limited number of plant species were examined.

Mycoheterotrophic plants associated with SAP fungi could have different life-history strategies from those associated with wood- and leaf litter-decaying fungi due to the different characteristics of these fungi. Wood-decaying fungi inhabit dead wood material, such as fallen logs, standing dead trees and stumps, and degrade wood lignocellulose [11]. The activity of wood-decaying fungi decreases during the process of wood decomposition due to nutrient depletion. Furthermore, along with the physical and chemical changes in the wood components, fungal community succession occurs with replacement of fungal species at different stages of wood decay [11]. Thus, wood-decaying fungi associated with MHPs decrease in abundance during the decomposition process, resulting in nutrient depletion for MHPs. This process led us to the following hypotheses: MHPs associated with wood-decaying fungi disappear from their habitats due to nutrient depletion after the complete decay of the host wood (Figure 1). These MHPs complete their life cycle before disappearing and colonizing neighbouring logs through seed dispersal. In contrast, leaf litter-decaying fungi colonize the topsoil and decompose plant leaf litter and soil organic matter [12], and can survive for a long time at individual sites where substantial leaf fall regularly occurs. Thus, MHPs associated with leaf litter-decaying fungi can survive for long periods at a single site where sufficient leaf fall occurs to sustain the associated leaf litter-decaying fungi (Figure 1).

To compare the life-history strategies of MHPs associated with wood- and leaf litterdecaying fungi, we monitored two mycoheterotrophic orchid species whose mycorrhizal fungi have been thoroughly studied. The mycoheterotrophic orchid Erythrorchis altissima (Blume) Blume is associated with a wide variety of wood-decaying fungi and is frequently found near large woody debris (Figure 2) [13]. It is a climbing, perennial hemiepiphytic species with both aerial and subterranean roots, and is distributed from warm-temperate to tropical forests in East to Southeast Asia [14]. We tagged E. altissima individuals inhabiting the study site $(300 \times 500 \mathrm{~m})$ and monitored these individuals for a maximum of five years. To test whether MHPs with wood-decaying fungi disappeared from their host wood after its complete decomposition, we monitored the survival period of the aboveground stems (in years) after tagging, and identified the tree species and decay status of the host wood. We also recorded whether the monitored stems flowered or fruited and how long the flowering or fruiting stems survived, because SAP-MHPs associated with wood-decaying fungi are expected to complete their life cycle before their disappearance. To determine the mature stem length at reproduction, the length of the monitored stems was also recorded every year. This orchid species develops both aerial and underground roots, and the aerial roots form fine-branched mycorrhizal root clumps when the roots are colonized by mycorrhizal fungi [13]. Our previous study revealed that the underground roots of E. altissima were also colonized by mycorrhizal fungi [13] but that this orchid species developed long, massive, underground roots in deep soils. The underground root system of this orchid is still poorly 
understood. Because it remains unknown to what extent the underground roots contribute to nutrient acquisition, we collected a whole-plant root system and observed whether the underground roots harboured mycorrhizal root clumps.

Gastrodia confusa

(Mycoheterotrophs with litter-decaying fungi)
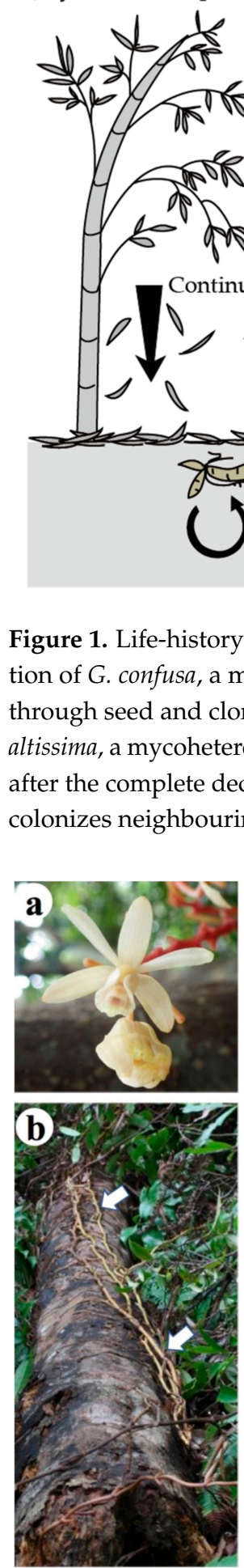
colonizes neighbouring logs through seed dispersal.
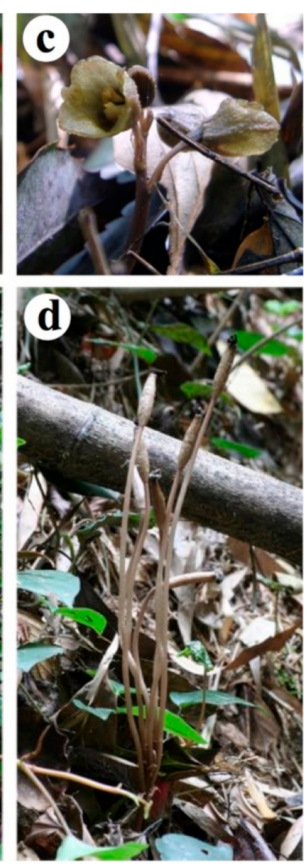

Erythrorchis altissima

(Mycoheterotrophs with wood-decaying fungi)

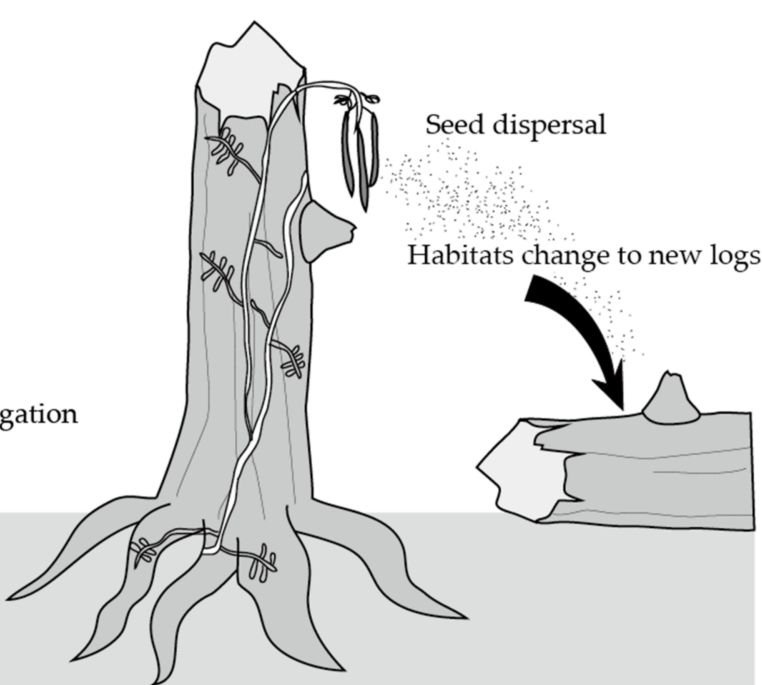

Figure 1. Life-history strategies of Gastrodia confusa (left) and Erythrorchis altissima (right). A population of G. confusa, a mycoheterotrophic plant associated with leaf litter-decaying fungi, can survive through seed and clonal propagation in a single habitat where sufficient leaf fall occurs. Erythrorchis altissima, a mycoheterotrophic plant associated with wood-decaying fungi, disappears from its habitat after the complete decay of the host wood. This plant completes its life cycle before it disappears and

Figure 2. (a) Flowers and (b) stems (white arrows) of Erythrorchis altissima climbing on a fallen dead wood. (c) Flowering and (d) fruiting plants of Gastrodia confusa. 
The mycoheterotrophic orchid Gastrodia confusa Honda et Tuyama is associated with leaf litter-decaying fungi within the genus Mycena and inhabits the litter-rich floors of bamboo forests (Figure 2) [15,16]. This orchid is distributed in warm-temperate regions from Japan to Taiwan [17]. It forms a tuber with mycorrhizal roots and appears aboveground during the reproductive period. Because SAP-MHPs associated with leaf litter-decaying fungi are expected to survive for a long time at the same site, we set up a permanent study plot $(12 \times 45 \mathrm{~m})$ and mapped the distribution of fruiting plants for six years. As precipitation and temperature affect the abundance of ECM-MHPs [4,6], the relationships between the abundance of fruiting plants and the seasonal and annual mean temperature and precipitation were examined. Underground plant growth in this orchid is poorly understood. Although Gastrodia elata Blume is clonally propagated by tubers [18], the reproductive strategy of $G$. confusa remains unknown. To assess the contribution of clonal and seed propagation to reproduction in G. confusa, we observed the underground organs and counted the number of fruits per fruiting stalk.

Our study represents the first long-term SAP-MHP field monitoring effort to compare the life-history strategies of MHPs associated with wood- and leaf litter-decaying fungi. This study will provide basic information on the unique life-history strategy of SAP-MHPs and an understanding of variations in the life-history traits of MHPs. Many MHPs are endangered worldwide due to habitat loss and climate change [2]. A poor understanding of the life-history of MHPs prevents their natural habitats from being appropriately conserved and managed. The conservation strategies for MHPs are expected to differ according to the characteristic features of the mycorrhizal fungi associated with the MHPs. Our study will provide valuable insights for the conservation of endangered MHPs.

\section{Materials and Methods}

\subsection{Erythrorchis altissima}

The study site for the investigation of E. altissima was a subtropical evergreen forest dominated by Castanopsis sieboldii (Makino) Hatus. (Figure S1) and located on Okinawa Island in Japan. E. altissima is usually quite rare in Japan and scarcely appears in these habitats, but individuals of this orchid species appeared at a high density at the study site. We monitored E. altissima inhabiting the forest $(300 \times 500 \mathrm{~m})$ every winter between 2015 and 2019. The surveys were conducted in November-December, except the survey for 2017, which was conducted in January 2018. We walked through the study site for two days and tagged newly found individuals in each survey between 2015 and 2017, and monitored them until 2019 (Figure S2). A total of 76 individuals were tagged with numbered plastic tags and observed during the five year period. In total, three cohorts were monitored: (1) 34 plants that were tagged in 2015 and monitored for five years, (2) 17 plants that were tagged in 2016 and monitored for four years, and (3) 25 plants that were tagged in 2017 and monitored for three years (Table 1 and Table S1). We recorded the state of the aboveground stems (living or dead), presence or absence of inflorescences and length of the aboveground stems. When the aboveground stems branched, the longest stem length was recorded. To test the possibility that a remaining underground organ may survive and regenerate stems after the death of the aboveground stems, we observed 27 individuals in the 2015-2019 cohort within two to three years after the death of the aboveground stems. We also recorded the species of the host trees that the E. altissima stems climbed and the decay status of the host trees (living, partially decayed, standing dead or fallen dead). The level of decay of host trees was surveyed according to Fukasawa et al. (2009) and assigned to five classes: (1) wood, hard; (2) wood, somewhat hard, a knife penetrates less than $1 \mathrm{~cm}$ into the wood; (3) wood, distinctly softened, a knife penetrates $\sim 1-4 \mathrm{~cm}$ into the wood, bark partly lost; (4) wood, strongly decayed, a knife penetrates $\sim 5-10 \mathrm{~cm}$ into the wood, bark lost in most places; and (5) wood, very decayed, a knife penetrates more than $10 \mathrm{~cm}$ into the wood, original log circumference not recognizable or hardly recognizable [19]. 
Table 1. Numbers of individuals of Erythrorchis altissima in the three cohorts monitored in this study.

\begin{tabular}{cccc}
\hline Monitoring Year & $\begin{array}{c}\text { No. of Individuals } \\
\text { Monitored }\end{array}$ & $\begin{array}{c}\text { No. of Individuals } \\
\text { That Flowered }\end{array}$ & $\begin{array}{c}\text { No. of Individuals } \\
\text { That Died within a } \\
\text { Year after Flowering }\end{array}$ \\
\hline $2015-2019$ & 34 & 28 & 21 \\
$2016-2019$ & 17 & 8 & 6 \\
$2017-2019$ & 25 & 11 & 6 \\
\hline Total & 76 & 47 & 33 \\
\hline
\end{tabular}

To observe the development of the underground root system, we collected a whole plant, including the aerial and underground roots, and measured the lengths of the roots. The roots were often branched, and all main and lateral roots longer than $10 \mathrm{~cm}$ in length were included in the total root length. The mycorrhizal root clumps that were thick and densely branched [13] were counted. The voucher specimens were deposited in the herbarium of the National Museum of Nature and Science, Japan (TNS), under accession numbers TNS8505964 and TNS8506020.

\subsection{Gastrodia confusa}

The study site for the investigation of G. confusa was a dense bamboo forest dominated by Phyllostachys edulis (Carrière) J.Houz. and Phyllostachys bambusoides Siebold et Zucc. (Figure S3) and located in a warm-temperate region in Fukuoka city, Fukuoka Prefecture, Japan. A permanent study plot $(12 \times 45 \mathrm{~m})$ was set up in an area of the forest floor where G. confusa individuals grew at a high density during the first monitoring year. The plot was divided into $2 \times 5 \mathrm{~m}$ subplots (a total of 54 subplots). This orchid species flowers in September and fruits in late October. Its flower stalks are approximately $10 \mathrm{~cm}$ in height during the flowering period but elongate to approximately $30 \mathrm{~cm}$ during the fruiting period. Because the plants are easily found during the fruiting season, we counted all emergent fruiting stalks in the permanent study plot in late October from 2003 to 2008. The number of fruits per stalk was also counted. To observe the underground organs, we collected three plants and deposited the voucher specimen under accession number TNS773661.

To evaluate whether the annual and seasonal temperature and precipitation affect the abundance of G. confusa fruiting stalks in the study plot, a regression analysis was performed with the "vegan" package in R [20]. Data on the mean temperature and precipitation between 2003 and 2008 in Fukuoka city were obtained from the Japan Meteorological Agency website (http:/ / www.jma.go.jp/jma/index.html, accessed on 2 December 2020) (Table S2). A multiple regression analysis was performed to test the relationships between the number of fruiting stalks and the annual temperature and precipitation. For the seasonal temperature and precipitation, we first used simple regressions between the number of fruiting stalks and each seasonal temperature and precipitation and used a stepwise multiple regression (Akaike information criterion (AIC) model selection) to select the optimal independent variables.

\section{Results}

\subsection{Erythrorchis altissima}

A total of 76 aboveground stems among the three cohorts were monitored for three to five years. Approximately $40 \%$ of the stems died within one year after tagging, and $70 \%$ of them died within two years (Figure 3). No stems survived for five years, and the maximum survival time among the 2015-2019 and 2016-2019 cohorts was four years. The average survival period of stems ranged from 1.8 to 2.0 years among the three cohorts, with the total average for all the stems being 1.9 years. To test the possibility that a remaining underground organ could regenerate new stems, we observed 27 individuals in the 2015-2019 cohort within two to three years after the death of the aboveground stems. No regeneration of new stems was observed in 25 of the individuals. We found newly 
formed stems at the same point where two of the previous stems had died, but those new stems did not flower and died within one year.
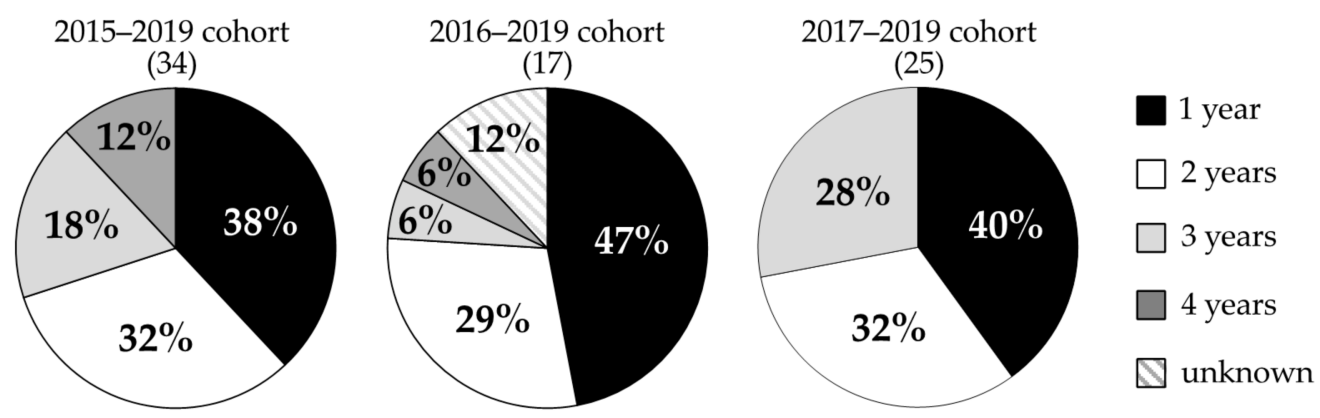

Figure 3. Frequency distribution of the survival period of the aboveground stems after tagging in three monitoring cohorts of Erythrorchis altissima. Numbers in parentheses indicate the number of individuals.

The flowering rates of the stems ranged from 44 to $82 \%$ among the cohorts, with an average of $62 \%$ (Table 1 ). Most flowering stems died within one year after flowering. The average mortality rate of flowering stems one year after flowering was $70 \%$ and ranged from 55 to $75 \%$ among the cohorts. The maximum stem length varied widely from 0.3 to $9.0 \mathrm{~m}$, with an average of $3.9 \mathrm{~m}$ (Table S1). The flowering rates of short stems were lower than those of long stems. Thirty percent of plants with stems shorter than $2 \mathrm{~m}$ in length flowered, while $79 \%$ of those with stems longer than $3 \mathrm{~m}$ in length flowered.

Eight tree species were identified as host trees of E. altissima (Table S1). The dominant species, Castanopsis sieboldii, accounted for $49 \%$ of all of the host trees, while other tree species (Cinnamomum daphnoides Siebold et Zucc., C. doederleinii Engl., C. yabunikkei H.Ohba, Elaeocarpus japonicus Siebold, Myrsine seguinii H.Lév., Syzygium buxifolium Hook. et Arn. and Ternstroemia gymnanthera (Wight et Arn.) Sprague) accounted for less than 4\%. In terms of host tree status, living and standing dead trees were the most frequent. These two statuses both accounted for $29 \%$ of the total, while fallen dead and partially decayed trees accounted for 13 and 16\%, respectively. Among the different decay levels of the host trees, the third level was the most frequent (37\%), followed by the fourth (21\%), first (16\%), second $(13 \%)$ and fifth (13\%) levels. The decay levels of the host trees increased over the years of monitoring in 14 of the 34 host trees that were evaluated for multiple years.

The underground organs of the observed individual harboured well-developed root systems (Figure S4; total root length $10.5 \mathrm{~m}$ ), with five mycorrhizal root clumps that were tightly attached to decayed tree roots. Aerial roots were also well developed $(10.5 \mathrm{~m}$ in total length) and harboured one root clump.

\subsection{Gastrodia confusa}

Fruiting plants appeared every year in the permanent plot $(12 \times 45 \mathrm{~m})$ during all monitored years between 2003 and 2008 (Figure 4). The number of fruiting stalks fluctuated widely during the six year period, from a minimum of 18 to a maximum of 108 . Fruiting stalks appeared in a limited number of subplots every year and were consistently absent from 26 of the 54 subplots (Figure 5). The average number of fruits per stalk was 1.7. We observed the underground organs of G. confusa and found tubers with and without roots (Figure S3). The plants clonally propagated from tubers, with two to three sister tubers attached to the mother tuber. 


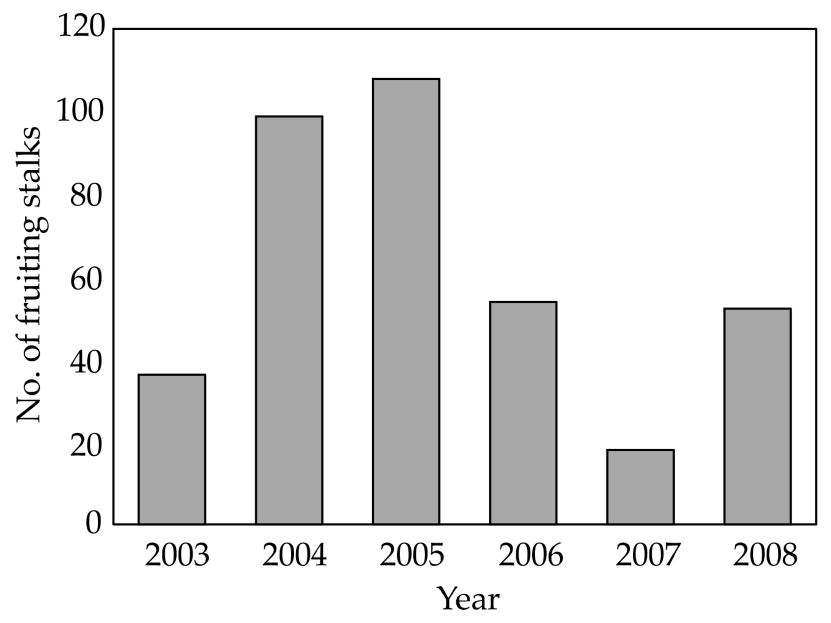

Figure 4. Number of fruiting stalks of Gastrodia confusa in the study plot $(12 \times 45 \mathrm{~m})$ between 2003 and 2008.

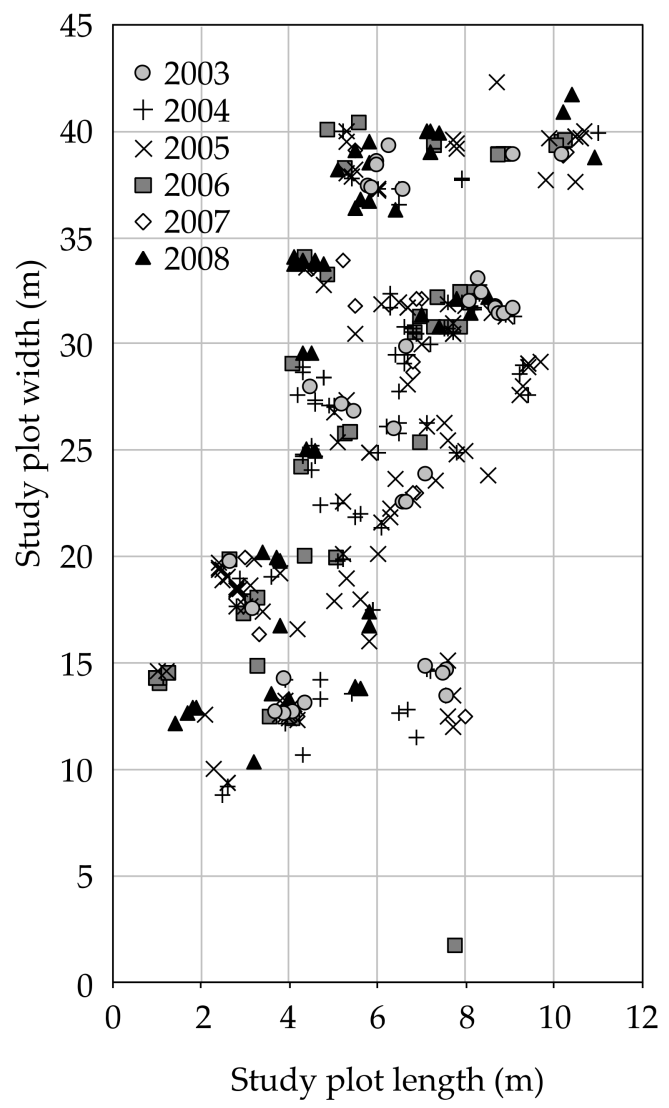

Figure 5. Map of Gastrodia confusa plants that emerged in the study plot $(12 \times 45 \mathrm{~m})$ in each year between 2003 and 2008. The plot was divided into $2 \times 5 \mathrm{~m}$ subplots.

The seasonal and annual mean temperatures remained almost consistent across the monitoring years, while the precipitation varied among them (Table S2). However, the number of fruiting stalks was not significantly correlated with the seasonal and annual mean temperature or precipitation during the monitoring years $(\mathrm{P}=0.91$ for the annual temperature and precipitation, $\mathrm{P}=0.15-0.76$ for the seasonal temperature, $\mathrm{P}=0.17-0.95$ for the seasonal precipitation). 


\section{Discussion}

\subsection{Erythrorchis altissima}

Our results showed that MHPs associated with wood-decaying fungi are not consistently observed at the same growing points (Figure 1), which supports our hypothesis. Approximately $70 \%$ of the aboveground stems died within two years after tagging, and most of the dead stems exhibited no regeneration of new stems from a remaining underground organ. The disappearance of individual plants from host trees may be caused by depletion of the carbon source, due to the complete decay of the wood. We evaluated the level of decay of host trees according to five stages, and the level increased in 14 of 34 host trees (Table S1). Intermediate decay levels (third and fourth) were the most common among the host trees, suggesting that E. altissima prefers wood-decaying fungi associated with intermediately decayed wood. As the decay level increases, the associated mycorrhizal fungi may disappear from within the woods, resulting in the death of E. altissima individuals on host trees. This strategy of being forced to change habitats within the short term may be unique to SAP-MHPs, especially the wood-decaying fungi-associated MHPs. Long-term survival in a single habitat can be achieved in populations of AM- or ECM-MHPs when mycorrhizal associations between AM or ECM fungi and their autotrophic host plants are stably maintained for a long period of time. In fact, one population of an ECM-MHP, Corallorhiza odontorhiza, has survived for 14 years within a $50 \times 80 \mathrm{~m}$ study plot [4].

Our results showed that over $60 \%$ of individuals transitioned from the vegetative to the reproductive phase (Table 1 ). We found that $68 \%$ of these individuals died within one year after flowering or fruiting. These results suggest that most individuals die after transition to the reproductive phase, likely due to depletion of the carbon source provided by the host trees. The MHPs associated with wood-decaying fungi are able to disperse their seeds before dying and establish seedlings in new habitats to maintain their populations (Figure 1). Plants with stems longer than $3 \mathrm{~m}$ in length flowered or fruited at higher rates than those with stems shorter than $2 \mathrm{~m}$ in length (Table S1). The average stem length of flowering E. altissima plants was $3.5 \mathrm{~m}$ on Kuchinoerabu Island, Kagoshima, Japan [21], which is consistent with our data. These results suggest that stems over $3 \mathrm{~m}$ in length could be suitable in size for flowering, while smaller stems could be in the juvenile vegetative phase. Seedlings that have established on logs with an insufficient source of carbon will develop short stems but die before transitioning to the reproductive phase.

Erythrorchis altissima likely utilizes not only aboveground logs but also underground dead wood as its carbon source. The host trees of this plant were both living and decayed (Table S1), although living trees seem to provide fewer carbon sources than partially or fully decayed trees for associated wood-decaying fungi. The underground organs of the surveyed individual harboured five mycorrhizal root clumps, while the aboveground stems had a single clump. This suggests that this individual mainly obtained carbon from the underground roots. Furthermore, all underground root clumps were attached to decayed tree roots, and the wood-decaying fungus Neonothopanus within white rot family Omphalotaceae was detected in the root sample (unpublished data). We identified eight individuals without aboveground host trees whose stems grew on the ground surface (Table S1). Such individuals may be associated with wood-decaying fungi utilizing underground decayed wood as a carbon source. Because associations with ECM Russula fungi have been found for E. altissima [13] and Erythrorchis cassythoides (A.Cunn. ex Lindl.) Garay [22], the underground roots of E. altissima could also be associated with ECM fungi.

The host tree species seemed to affect the longevity of E. altissima individuals. The longest lived aboveground stems survived for four years, and all of these individuals, for which we could identify the host tree, grew on Castanopsis sieboldii (Table S1). Because this tree species is an abundant large-diameter tree at the study site, C. sieboldii logs may provide a large carbon source and support diverse wood-decaying fungi, facilitating the survival of E. altissima. Although the host tree species were diverse, half of the host trees were C. sieboldii (Table S1). This tree species is a dominant component of Japanese evergreen forests. Umata et al. (1994) showed that E. altissima plants were found only in forests with 
C. sieboldii on Kuchinoerabu and Tokunoshima Islands, and that 47 of 48 individuals on Kuchinoerabu Island and 17 of 18 individuals on Tokunoshima Island were attached to C. sieboldii [21]. These results suggest that E. altissima may prefer C. sieboldii as a host tree.

\subsection{Gastrodia confusa}

Gastrodia confusa appeared in the permanent study plot in all years (2003-2008), which supports our hypothesis that MHPs associated with leaf litter-decaying fungi can survive at a single site for a long period. Reproduction through both seed and clonal propagation may contribute to the long-term survival of the G. confusa population within the permanent study plot. We found 18 to 108 fruiting stalks within the study plots (Figure 4), and the average number of fruits per stalk was 1.7. These results indicate continuous and abundant seed production during the monitoring years. Under cultivation conditions, this orchid species produces fruits 245 days after seed sowing [23], which suggests that dispersed seeds can mature within one year in natural habitats. The observation of the underground organs shows that G. confusa plants clonally propagate by producing tubers (Figure S3). Clonal propagation may help to maintain a high reproductive rate in years when seed production is insufficient. The mycoheterotrophic orchid Corallorhiza odontorhiza also propagates clonally by producing propagules from rhizomes, which may have contributed to the increase in the number of inflorescences within the study plot [4]. Clonal propagation may also affect the distribution of plants within the plot, as suggested for C. odontorhiza. Fruiting stalks appeared in very similar locations every year (Figure 5), suggesting that clonally propagated plants flowered near their mother plant in the following year.

The sufficient production of seeds and propagules indicated that the number of plant individuals within the study plot may be limited by the abundance of mycorrhizal fungi rather than by reproductive rates. G. confusa is associated mainly with leaf litter-decaying fungi of the genus Mycena $[15,16]$. Our study plot was located in a dense bamboo forest in which leaf litter and dead bamboo stems and roots had accumulated over the years (Figure S3). However, the available carbon within the small plot area $(12 \times 45 \mathrm{~m})$, as well as the abundance of associated Mycena fungi, may have been limited.

The number of fruiting stalks varied from 18 to 108 during the monitoring years (Figure 4). In the ECM-MHP Corallorhiza odontorhiza, the annual number of flowering plants was positively correlated with the growing season precipitation and negatively correlated with the winter mean temperature [4]. Years of extreme drought resulted in a decline in flowering stems in Corallorhiza striata [6]. In our study, the number of fruiting stalks was not significantly correlated with the annual and seasonal mean precipitation or temperature during the monitoring years. The distribution of a mycoheterotrophic orchid, Wullschlaegelia calcarata Benth., mainly associated with Mycena fungi [24,25], was influenced by leaf litter biomass and the component tree species represented in the leaf litter [7]. Factors related to leaf litter may affect the abundance and distribution of $G$. confusa, and a more detailed investigation of these factors is required.

\section{Conclusions}

This study represents the first long-term field monitoring effort for SAP-MHPs and suggests that the life-history strategies of SAP-MHPs differ between MHPs associated with wood- and leaf litter-decaying fungi. The life-history strategies of MHPs may even vary among MHPs associated with the same fungal categories. The mycoheterotrophic orchid Epipogium roseum (D.Don) Lindl., which is associated with wood-decaying fungi, propagates rapidly by producing clonal tubers [26]; in contrast, E. altissma has no propagules. This indicates that the reproductive strategies of SAP-MHPs associated with wood-decaying fungi can differ. Additional case studies would help to clarify the variation and differences in life-history strategies among MHPs. Our study also contributes to the conservation of MHPs. Conservation strategies for SAP-MHPs associated with wood- and leaf litterdecaying fungi will differ. The protection of microhabitats may be effective for maintaining populations of MHPs associated with leaf litter-decaying fungi, while a wide forest area 
will be required to maintain those of MHPs associated with wood-decaying fungi. A continuous supply of decaying wood (particularly wood that is sufficiently large to support plant growth) will be required in the habitats for these plants, but such wood may be sparse in some forests. Overall, this study provides insights into the diversification of the life-history traits of MHPs that could be strongly related to the characteristics of their associated fungi.

Supplementary Materials: The following are available online at https:/ / www.mdpi.com/article/10 .3390/d13040161/s1, Figure S1: Erythrorchis altissima (a) study site and (b) fruits. (c) Stems climbing on a living tree and (d) standing dead wood., Figure S2: Map of Erythrorchis altissima plants tagged in the study plot $(300 \times 500 \mathrm{~m})$ in each year between 2015 and 2017., Figure S3: Gastrodia confusa (a) study site, (b) plants with fruits and (c) flower buds., Figure S4: Underground root system of Erythrorchis altissima., Table S1: Monitoring data for the three cohorts (years 2015-2019, 2016-2019, 2017-2019) of E. altissima., Table S2: The number of fruiting stalks in the study plot and the monthly and annual mean temperature and precipitation in the study area (Fukuoka city) between 2003 and 2008.

Author Contributions: Conceptualization, Y.O.-T. and T.Y.; methodology, Y.O.-T., K.T. (Kenshi Tetsuka) and S.T.; investigation, Y.O.-T., K.T. (Kenshi Tetsuka), K.T. (Koichi Tone), S.T., M.K., S.A. and Y.Y.; writing, review and editing, Y.O.-T. and T.Y. All authors have read and agreed to the published version of the manuscript.

Funding: This research was funded by JSPS KAKENHI grant numbers 15K18597 and 17K07536 (to Y.O.) and $18 \mathrm{H} 02500$ (to T.Y.).

Institutional Review Board Statement: Not appliable.

Data Availability Statement: The data presented in this study are available in supplementary material here.

Acknowledgments: The authors thank T. Yahara for providing the opportunity to survey the Gastrodia confusa habitat; H. Enokimoto, I. Ganaha, T. Higashi, Y. Kawazoe, K. Rammitsu, T. Saito, T. Terada, T. Tetsuka, T. Yamaguchi and M. Moriguchi for supporting the field work; and Y. Fukasawa and A. Kinoshita for their valuable advice.

Conflicts of Interest: The authors declare no conflict of interest.

\section{References}

1. Leake, J. Tansley Review No. 69. The biology of myco-heterotrophic ('saprophytic') plants. New Phytol. 1994, 127, 171-216. [CrossRef]

2. Merckx, V.S.F.T. Mycoheterotrophy: The Biology of Plants Living on Fungi; Springer: Berlin/Heidelberg, Germany, 2013; ISBN 9781461452096.

3. Ogura-Tsujita, Y.; Yukawa, T.; Kinoshita, A. Evolutionary histories and mycorrhizal associations of mycoheterotrophic plants dependent on saprotrophic fungi. J. Plant Res. 2021, 134, 19-41. [CrossRef] [PubMed]

4. McCormick, M.K.; Whigham, D.F.; O’Neill, J.P.; Becker, J.J.; Sarah, W.; Rasmussen, H.N.; Bruns, T.D.; Taylor, D.L. Abundance and distribution of Corallorhiza odontorhiza reflect variations in climate and ectomycorrhizae. Ecol. Monogr. 2009, 79, 619-635. [CrossRef]

5. Shefferson, R.P.; McCormick, M.K.; Whigham, D.F.; O'Neill, J.P. Life history strategy in herbaceous perennials: Inferring demographic patterns from the aboveground dynamics of a primarily subterranean, myco-heterotrophic orchid. Oikos 2011, 120, 1291-1300. [CrossRef]

6. Verrier, J.T. A mycoheterotrophic orchid, Tomentelloid fungi, and drought in an Arizona Sky Island. Desert Plants 2017, 33, 3-9. [CrossRef]

7. Bergman, E.; Ackerman, J.D.; Thompson, J.; Zimmerman, J.K. Land-use history affects the distribution of the saprophytic orchid Wullschlaegelia calcarata in Puerto Rico's tabonuco forest. Biotropica 2006, 38, 492-499. [CrossRef]

8. Zhou, X.; Lin, H.; Fan, X.L.; Gao, J.Y. Autonomous self-pollination and insect visitation in a saprophytic orchid, Epipogium roseum (D.Don) Lindl. Aust. J. Bot. 2012, 60, 154-159. [CrossRef]

9. Suetsugu, K. Autogamous fruit set in a mycoheterotrophic orchid Cyrtosia septentrionalis. Plant Syst. Evol. 2013, 299, 481-486. [CrossRef]

10. Suetsugu, K. Gynomonoecy in a mycoheterotrophic orchid Eulophia zollingeri with autonomous selfing hermaphroditic flowers and putatively outcrossing female flowers. PeerJ 2020, 8, e10272. [CrossRef]

11. Stokland, J.N.; Siitonen, J.; Jonsson, B.G. Biodiversity in Dead Wood; Cambridge University Press: Cambridge, UK, 2012; ISBN 9781139025843 . 
12. Osono, T. Ecology of ligninolytic fungi associated with leaf litter decomposition. Ecol. Res. 2007, 22, 955-974. [CrossRef]

13. Ogura-Tsujita, Y.; Gebauer, G.; Xu, H.; Fukasawa, Y.; Umata, H.; Tetsuka, K.; Kubota, M.; Schweiger, J.M.I.; Yamashita, S.; Maekawa, N.; et al. The giant mycoheterotrophic orchid Erythrorchis altissima is associated mainly with a divergent set of wood-decaying fungi. Mol. Ecol. 2018, 27, 1324-1337. [CrossRef]

14. Comber, J.B. Orchids of Java; Betham-Moxon Trust: Surrey, UK, 1990.

15. Ogura-Tsujita, Y.; Gebauer, G.; Hashimoto, T.; Umata, H.; Yukawa, T. Evidence for novel and specialized mycorrhizal parasitism: The orchid Gastrodia confusa gains carbon from saprotrophic Mycena. Proc. R. Soc. B Biol. Sci. 2009, 276, 761-767. [CrossRef]

16. Kinoshita, A.; Ogura-Tsujita, Y.; Umata, H.; Sato, H.; Hashimoto, T.; Yukawa, T. How do fungal partners affect the evolution and habitat preferences of mycoheterotrophic plants? A case study in Gastrodia. Am. J. Bot. 2016, 103, 207-220. [CrossRef]

17. Yukawa, T. Orchidaceae. In Wild Flowers of Japan; Ohashi, H., Kadota, Y., Murata, J., Yonekura, K., Kihara, H., Eds.; Hoibonsha: Tokyo, Japan, 2015; pp. 178-231.

18. Xu, J.; Guo, S. Retrospect on the research of the cultivation of Gastrodia elata Bl, a rare traditional Chinese medicine. Chin. Med. J. 2000, 113, 686-692.

19. Fukasawa, Y.; Osono, T.; Takeda, H. Dynamics of physicochemical properties and occurrence of fungal fruit bodies during decomposition of coarse woody debris of Fagus crenata. J. For. Res. 2009, 14, 20-29. [CrossRef]

20. Oksanen, J.; Blanchet, F.G.; Fiendly, M.; Kindt, R.; Legendre, P.; McGlinn, D.; Minchin, P.R.; O’Hara, R.B.; Simpson, G.L.; Solymos, P.; et al. Vegan: Community Ecology Package. Available online: http://cran.r-project.org/package=vegan (accessed on 2 December 2020).

21. Umata, H. The habitat and habit of a chlorophyll-free orchid, Erythrorchis altissima (Bl.) Bl. Acta Phytotax. Geobot. 1994, 45, 131-138.

22. Dearnaley, J. The fungal endophytes of Erythrorchis cassythoides-Is this orchid saprophytic or parasitic? Australas. Mycol. 2006, $25,51-57$.

23. Shimaoka, C.; Fukunaga, H.; Inagaki, S.; Sawa, S. Artificial cultivation system for Gastrodia spp. and identification of associated mycorrhizal fungi. Int. J. Biol. 2017, 9, 27-34. [CrossRef]

24. Martos, F.; Dulormne, M.; Pailler, T.; Bonfante, P.; Faccio, A.; Fournel, J.; Dubois, M.P.; Selosse, M.A. Independent recruitment of saprotrophic fungi as mycorrhizal partners by tropical achlorophyllous orchids. New Phytol. 2009, 184, 668-681. [CrossRef]

25. Hatté, C.; Zazzo, A.; Selosse, M.A. The radiocarbon age of mycoheterotrophic plants. New Phytol. 2020, 227, 1284-1288. [CrossRef]

26. Yagame, T.; Yamato, M.; Mii, M.; Suzuki, A.; Iwase, K. Developmental processes of achlorophyllous orchid, Epipogium roseum: From seed germination to flowering under symbiotic cultivation with mycorrhizal fungus. J. Plant Res. 2007, 120, $229-236$. [CrossRef] [PubMed] 